\title{
Multiorgan failure following gastroenteritis: a case report
}

\author{
Joseph De Zylva ${ }^{1 *}$ (D) James Padley ${ }^{2}$, Rassam Badbess ${ }^{3}$ and Maneesha Dedigama ${ }^{3}$
}

\begin{abstract}
Background: This report highlights the first published case of fatal septic shock associated with Clostridium perfringens and Enterococcus avium bacteremia due to infective gastroenteritis.

Case presentation: We report a case of hepatic infarction, abscess, and death following gastroenteritis in a 63year-old Aboriginal man who initially presented to a rural hospital with suspected food poisoning. The patient had persistent fever and was commenced on empirical antibiotics. His blood culture results were positive for Clostridium perfringens and Enterococcus avium. He was transferred to a tertiary center but developed organ failure and refractory shock. Initial computed tomography of the abdomen was unremarkable, but repeat imaging showed small bowel enteritis, hepatic abscess, and infarction as a result of portal vein septic thromboembolism. Despite maximal intensive care treatment, including percutaneous drainage of hepatic abscess and broad antibiotic cover, the patient died 6 days after initial presentation.

Conclusions: This case highlights the rare but commonly fatal course of sepsis associated with Clostridium perfringens bacteremia and demonstrates detrimental effects of coinfection with Enterococcus avium, including potential for rapidly seeding abscess formation. Lessons for rural practice are highlighted, including the need for urgent and early referral for intensive care support, particularly for patients with complex comorbidities.
\end{abstract}

Keywords: Clostridium perfringens, Enterococcus avium, Sepsis, Gastroenteritis, Rural/regional hospital

\section{Background}

Both Clostridium perfringens and Enterococcus avium are implicated in food poisoning from poultry. Historical data suggest that $C$. perfringens is the second most common cause of food poisoning after Staphylococcus aureus [1]. E. avium accounts for only $2.4 \%$ of cases of Enterococcus bacteremia and has been associated with visceral abscess formation $[2,3]$.

Since 1990, only 50 cases of C. perfringens bacteremia have been described $[4,5]$. Sepsis from $C$. perfringens can be rapidly fatal, often because of massive hemolysis, with a reported mortality of $74 \%$ [4]. Few effective treatment options exist, although a survival benefit may be

\footnotetext{
* Correspondence: joseph.dezylva@gmail.com

'Medical Officer, South Coast District Hospital, 56 Bay Road, Victor Harbor, SA 5211, Australia

Full list of author information is available at the end of the article
}

conferred by early antibiotic treatment, surgical source control, and/or hyperbaric oxygen therapy [4]. C. perfringens sepsis is often unrecognized at initial clinical presentation; however, the source of infection is usually related to underlying pathology involving the uterus, colon, or biliary tract $[4,5]$. Although foodborne $C$. perfringens bacteremia has been described, fatal cases are exceedingly rare [6]. $E$. avium sepsis is poorly understood, owing to its relative infrequency of occurrence. We report a unique case of fatal complications associated with $C$. perfringens and $E$. avium septicemia following an initial foodborne illness.

\section{Case presentation}

A 63-year-old Aboriginal man was referred by a general practitioner to a rural hospital emergency department. The patient presented with 24 hours of epigastric pain, vomiting, watery diarrhea, generalized muscle aches, and

\section{BMC}

(c) The Author(s). 2020 Open Access This article is licensed under a Creative Commons Attribution 4.0 International License, which permits use, sharing, adaptation, distribution and reproduction in any medium or format, as long as you give appropriate credit to the original author(s) and the source, provide a link to the Creative Commons licence, and indicate if changes were made. The images or other third party material in this article are included in the article's Creative Commons licence, unless indicated otherwise in a credit line to the material. If material is not included in the article's Creative Commons licence and your intended use is not permitted by statutory regulation or exceeds the permitted use, you will need to obtain permission directly from the copyright holder. To view a copy of this licence, visit http://creativecommons.org/licenses/by/4.0/ The Creative Commons Public Domain Dedication waiver (http://creativecommons.org/publicdomain/zero/1.0/) applies to the data made available in this article, unless otherwise stated in a credit line to the data. 
fever. The preceding night, the patient had eaten a piece of chicken that he had cooked after it had been refrigerated for a few days. The patient was an ex-smoker, was moderately obese, and had long-standing type 2 diabetes being treated with insulin and complicated by diabetic nephropathy (baseline serum creatinine 300-320 $\mu \mathrm{mol} /$ $\mathrm{L}$ ) and peripheral vascular disease, ischemic cardiomyopathy (New York Heart Association [NYHA] class II symptoms), hypertension, and depression. Over the preceding 2 years, he had been managed in the outpatient heart failure clinic with review every $6-8$ weeks. His heart failure symptoms had been deemed to be stable at his last review 6 weeks before presentation. The patient's regular medications were low-dose aspirin, bisoprolol, fluvoxamine, gliclazide MR, insulin glargine, fenofibrate, simvastatin, and inhaled fluticasone/salmeterol. The patient lived alone and was functionally independent with activities of daily living.

Upon presentation to hospital, his initial examination was remarkable only for fever. Blood biochemistry showed raised inflammatory markers and chronically elevated creatinine (Table 1). The patient was admitted to the general medical ward of a rural district hospital for supportive treatment with a presumptive diagnosis of infective gastroenteritis. Initial management included intravenous fluid rehydration and antiemetics. His fluid status was monitored, and his regular medications, including insulin and inhaled bronchodilators, were continued.

Over the next 24 hours, the patient continued to have intermittent high fevers. Empirical antibiotics were commenced (intravenous piperacillin/tazobactam $4.5 \mathrm{~g}$ three times daily). Blood cultures subsequently grew $C$. perfringens and E. avium; both organisms were sensitive to penicillin. Computed tomography $(\mathrm{CT})$ of the abdomen and pelvis demonstrated cholelithiasis but was otherwise normal (Fig. Fig. 1). Specialist infectious disease advice was sought on two occasions, which confirmed appropriate antibiotic management. The patient continued to remain clinically stable.

Viral nasopharyngeal swabs were also positive for human metapneumovirus. The results of fecal nucleic acid testing were negative for other common pathogenic organisms, including enteric viruses, parasites, and bacteria. The results of viral and autoimmune hepatitis screening were negative. Urine culture performed prior to initiating antibiotics was clear. Blood film obtained 48 hours after admission showed neutrophilic toxic changes.

On the third day after presentation, the patient became visibly jaundiced and complained of mild intermittent epigastric pain. Blood biochemistry showed acute renal and hepatic injury and hyperbilirubinemia suggestive of intravascular hemolysis (Table 1). The patient was urgently transferred to a tertiary center, given the risk of deterioration.

The patient's condition significantly deteriorated over the next 24 hours, and he was admitted to intensive care with septic shock and renal failure. He required support with multiple inotropes and dialysis. Antibiotic cover was extended to include vancomycin, meropenem, and

Table 1 Hematology and biochemistry results in a patient admitted with gastroenteritis

\begin{tabular}{|c|c|c|c|c|c|c|}
\hline & 2 months prior & Day 1: $1745 \mathrm{~h}$ & Day 3: $1350 \mathrm{~h}$ & Day 3: $2030 \mathrm{~h}$ & Day 4: $1715 \mathrm{~h}$ & Day 5: $0510 \mathrm{~h}$ \\
\hline $\mathrm{Hb}, \mathrm{g} / \mathrm{L}$ & 136 & 136 & 118 & 119 & 88 & 83 \\
\hline Leukocytes, $\times 10^{9} / \mathrm{L}$ & 7.09 & 10.55 & 11.48 & 9.44 & 14.02 & 7.61 \\
\hline Platelets, $\times 10^{9} / \mathrm{L}$ & 299 & 180 & 112 & 90 & 72 & 59 \\
\hline Neutrophils, $\times 10^{9} / \mathrm{L}$ & 4.91 & 10.05 & 10.1 & 8.5 & 12.9 & 6.9 \\
\hline Creatinine, $\mu \mathrm{mol} / \mathrm{L}$ & 303 (baseline 300-320) & 327 & 460 & 577 & 377 & 322 \\
\hline Urea, mmol/L & 13.4 & 16.6 & 26 & 28.3 & 18.3 & 14.3 \\
\hline Anion gap, mmol/L & 20 & 23 & 29 & 32 & 26 & 26 \\
\hline Albumin, $\mathrm{g} / \mathrm{L}$ & 35 & 33 & 24 & 21 & 30 & 25 \\
\hline Bilirubin, $\mu \mathrm{mol} / \mathrm{L}$ & 4 & 66 & 414 & 380 & 355 & 345 \\
\hline$A L P, U / L$ & 91 & 112 & 100 & 108 & 95 & 104 \\
\hline$A L T, U / L$ & 33 & 330 & 2948 & 2155 & 2540 & 2622 \\
\hline AST, U/L & 27 & 352 & 3663 & 2266 & 3531 & 3712 \\
\hline GGT, U/L & 54 & 216 & 189 & 164 & 101 & 90 \\
\hline $\mathrm{LDH}, \mathrm{U} / \mathrm{L}$ & 213 & 464 & 2010 & 1123 & 1831 & 1863 \\
\hline INR & 0.9 & & 1.7 & 1.4 & 1.3 & \\
\hline
\end{tabular}

Abbreviations: ALP Alkaline phosphatase, ALT Alanine aminotransferase, AST Aspartate aminotransferase, GGT Y-Glutamyl transferase, Hb Hemoglobin, INR International normalized ratio, $L D H$ Lactate dehydrogenase

Day 1 indicates the evening of presentation to the rural emergency department. On day 3, the patient developed intravascular hemolysis, acute liver and renal injury and was transferred to a tertiary center. Baseline blood results from 2 months prior to admission are also shown 


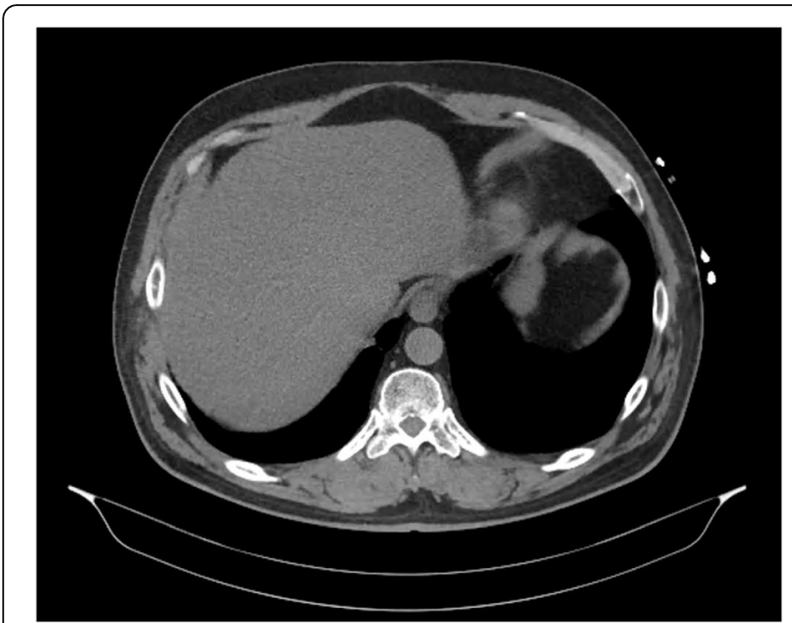

Fig. 1 Computed tomography (CT) of the abdomen and pelvis in a patient with suspected gastroenteritis. Image was obtained within 24 hours of presentation to the hospital. CT demonstrated cholelithiasis but no other abnormality

clindamycin (Table 2). Repeat CT of the abdomen and pelvis demonstrated small bowel enteritis, hepatic infarction, and portal vein thrombosis suspected to be septic thromboembolism. CT also demonstrated several hepatic hypodensities consistent with multiple abscesses, the largest measuring $41 \mathrm{~mm}$ in diameter (Fig. 2). Ultrasound-guided drainage was performed, and $35 \mathrm{ml}$ of hemoturbid fluid was aspirated. The result of culture of the hepatic abscess was positive for E. avium.

The patient developed refractory septic and cardiogenic shock and required intubation and ventilation. Intubation was complicated by bronchial bleeding that required transfusion and endobronchial intervention. The patient had been temporarily commenced on therapeutic heparin for portal vein thrombosis; however, this was rapidly reversed with Prothrombinex ${ }^{\circ}$ VF (CSL Behring, Victoria, Australia) [7]. Transthoracic

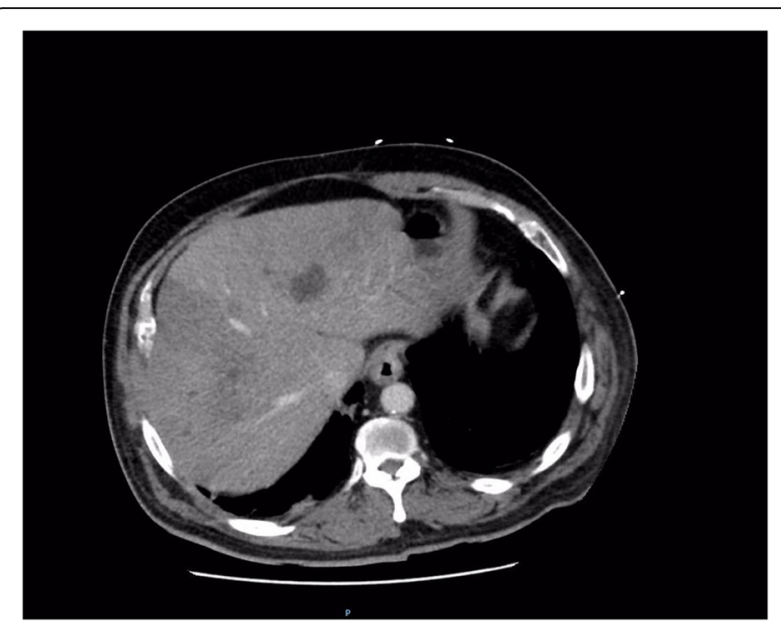

Fig. 2 Computed tomography (CT) of the abdomen and pelvis 72 hours after presentation to the hospital showing multiple lobulated intrahepatic collections, infarction of hepatic segments 5 and 8, and septic occlusion of the portal vein. There were no gas locules associated with the abscesses. CT also demonstrated small bowel enteritis (not shown)

echocardiography demonstrated severe left ventricular (LV) dysfunction (estimated LV ejection fraction, 21\%) but no evidence of valvular dysfunction or infective endocarditis. Despite maximal intensive care support, including intra-aortic balloon counter pulsation, the patient died 2 days after admission to intensive care, 6 days after his initial presentation.

\section{Discussion}

The dramatic clinical course in our patient's case demonstrates a rapid clinical deterioration associated with complications from $C$. perfringens and E. avium sepsis due to infective gastroenteritis. In our patient's case, despite recognition of liver injury and hemolysis and early referral to a tertiary center, early antibiotic treatment

Table 2 Summary of antibiotic management of a 63-year-old aboriginal patient with infective gastroenteritis complicated by sepsis and organ failure

\begin{tabular}{|c|c|c|c|c|c|}
\hline & \multicolumn{5}{|c|}{ Day of admission } \\
\hline & 1 & 2 & 3 & 4 & 5 \\
\hline \multirow[t]{4}{*}{$\begin{array}{l}\text { Antibiotic } \\
\text { regimen }\end{array}$} & & $\begin{array}{l}\text { Piperacillin/ } \\
\text { tazobactam } \\
4.5 \mathrm{~g} \text { three times } \\
\text { daily }\end{array}$ & $\begin{array}{l}\text { Piperacillin/tazobactam } \\
4.5 \mathrm{~g} \text { three times daily }\end{array}$ & $\begin{array}{l}\text { Piperacillin/tazobactam } \\
2.25 \mathrm{~g} \text { three times daily }{ }^{\text {a }}\end{array}$ & $\begin{array}{l}\text { Piperacillin/tazobactam } \\
2.25 \mathrm{~g} \text { three times daily }\end{array}$ \\
\hline & & & $\begin{array}{l}\text { Vancomycin } 2.5-g \text { loading dose then } \\
\text { continuous infusion }\end{array}$ & $\begin{array}{l}\text { Vancomycin continuous } \\
\text { infusion }\end{array}$ & $\begin{array}{l}\text { Vancomycin continuous } \\
\text { infusion }^{\text {b }}\end{array}$ \\
\hline & & & Clindamycin 600 mg three times daily & $\begin{array}{l}\text { Clindamycin } 600 \text { mg three } \\
\text { times daily }\end{array}$ & $\begin{array}{l}\text { Clindamycin } 600 \text { mg three } \\
\text { times daily }\end{array}$ \\
\hline & & & & $\begin{array}{l}\text { Meropenem } 1 \mathrm{~g} \text { three times } \\
\text { daily }\end{array}$ & $\begin{array}{l}\text { Meropenem } 1 \mathrm{~g} \text { three times } \\
\text { daily }\end{array}$ \\
\hline
\end{tabular}

On day 2, blood cultures from day 1 were positive for Clostridium perfringens and Enterococcus avium sensitive to penicillin. On day 3 , the patient was transferred from a rural district hospital to a tertiary center, and his condition deteriorated over the next 24 hours

${ }^{\text {a }}$ Renally adjusted dose

${ }^{\mathrm{b}}$ Discontinued on day 5 after specialist advice to de-escalate antibiotic regimen 
and maximal intensive care support did not lead to recovery.

C. perfringens sepsis may present with nonspecific symptoms or with fever and abdominal pain and is associated with leukocytosis, anemia, thrombocytopenia, and liver dysfunction. C. perfringens bacteremia has been reported to arise from intra-abdominal (52.7\%) or lower respiratory tract sources $(19.4 \%)$ or to be associated with polymicrobial infection (54.8\%) [8]. Previous case reports suggest that source control may lead to improved outcomes, although these cases were associated with a clear focus of infection $[4,5]$. In our patient's case, limited ultrasound-guided aspiration of a hepatic abscess was able to be performed; however, the disseminated sepsis and multiple small hepatic abscesses precluded other surgical intervention. Hyperbaric oxygen therapy was not indicated in the present case, although its use has been described in previous case reports in which there was a necrotizing focus of $C$. perfringens infection [4].

E. avium bacteremia is uncommon and accounts for only 2-3\% of cases of Enterococcus bacteremia [9]. Little is understood regarding the clinical presentation of $E$. avium sepsis, given its infrequent occurrence, although it has a poor prognosis with an associated mortality rate of $24.5 \%$ [10]. E. avium disseminates predominantly from biliary (50.9\%) or intra-abdominal sources (24.5\%), and Escherichia coli is commonly detected in coinfection [10]. Risk factors for Enterococcus sepsis include biliary disease, diabetes, and solid cancers, particularly of hepatobiliary or gastrointestinal origin [9].

Both $C$. perfringens and E. avium are potentially pathogenic organisms with poor risk profiles when associated with systemic infection. This case highlights systemic effects of $C$. perfringens endotoxemia together with rapidly seeding abscess formation from $E$. avium bacteremia. In our patient's case, early antibiotic management and limited source control did not prevent overwhelming sepsis and subsequent organ failure. The source of infection in this case could have been related to food preparation or precipitated by initial gastroenteric illness. It is not possible to distinguish the contribution of individual organisms to our patient's initial clinical presentation and rapid deterioration, although this case highlights the detrimental effects of coinfection.

Our patient had risk factors and complex comorbidities that may have predisposed him to disseminated infection and subsequent organ failure. Diabetes, chronic kidney disease, and cardiac failure are independent risk factors of mortality from sepsis. The patient is likely to have had poor physiological reserve, which limited his ability to compensate for gastroenteric illness and endotoxemia. The risk of mortality from sepsis is increased by 2.27 times for NYHA class II heart failure and 2.36 times for estimated glomerular filtration rate (eGFR) less than $45 \mathrm{ml} /$ minute compared with NYHA class I or eGFR $>60 \mathrm{ml} /$ minute, respectively [11, 12]. Concurrent human metapneumovirus infection combined with endobronchial trauma may have further contributed to the patient's poor outcome in this case.

\section{Conclusions/lessons for practice}

- Suspect food poisoning in patients with multiple comorbidities

- Anticipate exaggerated physiological insults (e.g., associated with dehydration)

- Recognize complications associated with bacteremia; consider early referral and/or transfer

- Clostridium perfringens bacteremia:

- High rate of mortality associated with complications, including hemolysis

- Consider early transfer to a tertiary center hospital with intensive care capability

- E. avium bacteremia:

- Rare cause of gastrointestinal illness; when present, consider polymicrobial infection and seeding abscess formation necessitating repeat imaging and drainage for source control

Acknowledgements

Not applicable.

Authors' contributions

The authors read and approved the final manuscript.

Funding

Not applicable.

Availability of data and materials

Not applicable.

Ethics approval and consent to participate

Not applicable.

Consent for publication

Written informed consent was obtained from the patient's next of kin for publication of this case report and any accompanying images. A copy of the written consent is available for review by the Editor-in-Chief of this journal.

Competing interests

The authors declare that they have no competing interests.

Author details

${ }^{1}$ Medical Officer, South Coast District Hospital, 56 Bay Road, Victor Harbor, SA 5211, Australia. ${ }^{2}$ Clinical Educator, Rural and Remote Health, College of Medicine and Public Health, Flinders University, Flinders Drive, Bedford Park, SA 5042, Australia. ${ }^{3}$ Consultant General Physician, Flinders Medical Centre, Flinders Drive, Bedford Park, SA 5042, Australia. 
Received: 30 June 2019 Accepted: 21 May 2020

Published online: 21 June 2020

\section{References}

1. Shandera WX, Tacket CO, Blake PA. Food poisoning due to Clostridium perfringens in the United States. J Infect Dis. 1983;147(1):167-70.

2. Patel R, Keating MR, Cockerill FR, Steckelburg JM. Bacteremia due to Enterococcus avium. Clin Infect Dis. 1993;17(6):1006-11.

3. Tan CK, Lai CC, Wang JY, Lin SH, Lio CH, Huang YT, Wang CY, Lin HI, Hsueh PR. Bacteremia caused by non-faecalis and non-faecium Enterococcus species at a medical center in Taiwan, 2000 to 2008. J Infect. 2010;61(1):34-43.

4. Simon TG, Bradley J, Jones A, Carino G. Massive intravascular hemolysis from Clostridium perfringens septicemia: a review. J Intensive Care Med. 2014; 29(6):327-33.

5. van Bunderen CC, Bomers MK, Wesdorp E, Peerbooms P, Veenstra J. Clostridium perfringens septicaemia with massive intravascular haemolysis: a case report and review of the literature. Neth J Med. 2010;68(9):343-6.

6. Scallan E, Hoekstra RM, Angulo FJ, Tauxe RV, Widdowson MA, Roy SL, Jones $J$, Griffin PM. Foodborne illness acquired in the United States-major pathogens. Emerg Infect Dis. 2011;17(1):7-15.

7. CSL Behring. Australian Product Information. Prothrombinex ${ }^{\oplus}$ VF (Human prothrombin complex) Powder and diluent for solution for injection. 2020 https://www.cslbehring.com.au/products/products-list.

8. Yang CC, Hsu PC, Chang HJ, Cheng CW, Lee MH. Clinical significance and outcomes of Clostridium perfringens bacteremia-a 10-year experience at a tertiary care hospital. Int J Infect Dis. 2013;17(11):e955-60.

9. Billington EO, Phang SH, Gregson DB, Pitout JDD, Ross T, Church DL, Laupland KB, Parkins MD. Incidence, risk factors, and outcomes for Enterococcus spp. blood stream infections: a population-based study. Int J Infect Dis. 2014;26:76-82

10. Na S, Park HJ, Park KH, Cho OH, Chong YP, Kim SH, Lee SO, Sung H, Kim MN, Jeong JY, Kim YS, Woo JH, Choi SH. Enterococcus avium bacteremia: a 12-year clinical experience with 53 patients. Eur J Clin Microbiol Infect Dis. 2012;31:303-10.

11. Wang HE, Gamboa C, Warnock DG, Muntner P. Chronic kidney disease and risk of death from infection. Am J Nephrol. 2011;34(4):330-6.

12. Walker AMN, Drozd M, Hall M, Patel PA, Paton M, Lowry J, Gierula J, Byrom R, Kearney L, Sapsford RJ, Witte KK, Kearney MT, Cubbon RM. Prevalence and predictors of sepsis death in patients with chronic heart failure and reduced left ventricular ejection fraction. J Am Heart Assoc. 2018;7(20): e009684.

\section{Publisher's Note}

Springer Nature remains neutral with regard to jurisdictional claims in published maps and institutional affiliations.

Ready to submit your research? Choose BMC and benefit from:

- fast, convenient online submission

- thorough peer review by experienced researchers in your field

- rapid publication on acceptance

- support for research data, including large and complex data types

- gold Open Access which fosters wider collaboration and increased citations

- maximum visibility for your research: over $100 \mathrm{M}$ website views per year

At $\mathrm{BMC}$, research is always in progress.

Learn more biomedcentral.com/submissions 